\title{
Analysis of Inverse Rayleigh Distribution based on Lower Record Values
}

\author{
Summaira Manzoor ${ }^{1,2, *}$ and Ahmed Zogo Memon ${ }^{1}$ \\ ${ }^{1}$ Department of Statistics, College of Statistical and Actuarial Sciences, University \\ of the Punjab, Lahore \\ ${ }^{2}$ Department of Statistics, University of Azad Jammu and Kashmir, \\ Muzaffarabad, Pakistan \\ *ssummaira@gmail.com
}

\begin{abstract}
In this research paper, the estimation of the parameters of Inverse Rayleigh distribution is considered from lower record values by using three different methods. We used Lloyd's Method, Gupta's Method and Weiss (1961) Approximation to find the estimates of our proposed distribution. The comparisons between the performances of theses estimation methods, for location and scale parameters of Inverse Rayleigh distribution have been made in terms of relative efficiency by using both numerical and graphical way of presentation. Critical study is made on the Exact and approximate methods of estimation. An alternate best linear estimator gives very poor approximation in case of Inverse Rayleigh distribution. So approximate method known as Weiss's method is used which gives high efficiency with Lloyd method. This is the method of estimating the single parameter only that is the scale parameter. But in this study we modified this method for estimating the location parameter also. These location and scale estimator are compared with the Lloyd method and concluded that in all cases efficiency is very high so this approximation is good as compared to Gupta's method.
\end{abstract}

Keywords: Record values, Location parameter, Scale parameter

\section{Introduction}

Record values are of great importance to scientists and engineers in several real life problems involving weather, economic, and support data. For example, it is very important for climatologists and hydrologists to predict the flood level of a river that is greater than the previous ones. In the same way, Prediction about the magnitude of an earthquake which has a greater magnitude than the previous ones, in a given region, is a matter of great importance to seismologists as well. Moreover, record values are also important to ordinary people regarding all kinds of strange and extreme phenomenon and talents. A lot of work has been done on characterizations, asymptotic theory and generalizations of record values but not much has been done on statistical inference based on record values. Chandler [1] introduced the theory of record values for the first time, in his publication under the title "The distribution and frequency of record values". Since then, many authors have studied record value for example Balakrishan and Chan [2] discussed the record values arising from a normal distribution. After computing the means, variances and covariance's of the record values, they determined the best linear unbiased estimates (BLUE) based on the first $\mathrm{n}$ upper record values.

Ahsanullah [3] gave the properties of Rayleigh distribution based on upper record values and presented tables of means and variance covariance's for sample of size up to order 10. Soliman et al., [4] developed a Bayesian analysis in the context of record values

${ }^{*}$ Corresponding Author 
from the two parametric Weibull distribution. Hendi et al., [5] have obtained the Bayes estimators of parameters based on upper record values from Rayleigh distribution. Ahmadi and Doostparast [6] discussed the statistical inference based on k-records. Sultan [7] used the lower record values from the Inverse Weibull distribution to develop and discuss different methods of estimation in two different cases, when the shape parameter is known and when both the shape and scale parameters are unknown. Azaz and Akhter [8] derived the BLUE (Lloyd's Method) and an alternate BLUE (Gupta's Method) for Rayleigh distribution based on upper record values and concluded that Gupta method gives the high efficiency and can be replaced with Lloyd method for large value of $n$. But this conclusion is not hold for Inverse Rayleigh distribution (IRD). Dey and Dey [9] derived the Bayes estimators for the unknown parameter of a Rayleigh distribution from upper record values. Amin [10] proposed the maximum likelihood estimator and Bayes' estimator for the stress strength reliability based on lower record values. Hamid and Imtiyaz [11] developed the distributional properties of the order statistics; upper and lower records have been utilized to characterize distribution of interest. One sided random dilation and contraction are utilized to obtain the distribution of non-adjacent ordered statistics and also their important deductions were discussed.

Let $X_{L(1)}, X_{L(2)}, X_{L(3)}, \ldots, X_{L(r)}$ be the first $r$ lower record values from the IRD with Probability density function (pdf) as

$$
f(x)=\frac{2 \lambda^{2}}{(y-\theta)^{3}} e^{-\frac{\lambda^{2}}{(x-\theta)^{2}}} \quad \theta<x<\infty, \lambda>0 .
$$

where $\lambda$ is a scale parameter and $\theta$ is a location parameter of IRD.

This paper is devoted to obtain and compare several techniques of estimation based on lower record values. Critical study is made on the Exact and approximate methods of estimation. A discussion of the BLUE (Lloyd's ) is considered in Section 2. In Section 3, estimation through Gupta's method is investigated. In Section 4, Weiss approximation for estimation of parameters is discussed. Finally, conclusions are drawn in Section 5.

\section{Lloyd's Method for Lower Record Values}

Suppose $\mathrm{X}_{1}, \mathrm{X}_{2}, \ldots$, is a sequence of i.i.d then $\mathrm{X}_{\mathrm{L}(1)}, \mathrm{X}_{\mathrm{L}(2)}, \ldots, \mathrm{X}_{\mathrm{L}(\mathrm{n})}$ are the corresponding lower record variables. Let us make the transformation

$$
\mathrm{y}_{\mathrm{L}(\mathrm{i})}^{(\mathrm{n})}=\frac{\mathrm{x}_{\mathrm{L}(\mathrm{i})}^{(\mathrm{n})}-\theta}{\lambda} \quad \mathrm{i}=1,2, \ldots \ldots, \mathrm{n}
$$

and $\left(\mathrm{y}_{\mathrm{L}(1)}^{(\mathrm{n})}, \mathrm{y}_{\mathrm{L}(2)}^{(\mathrm{n})} \ldots \ldots \ldots \ldots . . . . \mathrm{y}_{\mathrm{L}(\mathrm{n})}^{(\mathrm{n})}\right)$ are then the realizations of a set of order random variables

$\mathrm{Y}_{\mathrm{L}(1)}^{(\mathrm{n})}, \mathrm{Y}_{\mathrm{L}(2)}^{(\mathrm{n})} \ldots \ldots \ldots \ldots . . . \mathrm{Y}_{\mathrm{L}(\mathrm{n})}^{(\mathrm{n})}$

Let us denote

$$
\begin{aligned}
& \mathrm{E}\left(\mathrm{Y}_{\mathrm{L}(\mathrm{i})}^{(n)}\right)=\alpha_{\mathrm{L}(\mathrm{i})}^{(n)}, \operatorname{Var}\left(\mathrm{Y}_{\mathrm{L}(\mathrm{i})}^{(n)}\right)=\mathrm{V}_{\mathrm{L}(\mathrm{ii})}^{(\mathrm{n})} \\
& \mathrm{E}\left(\mathrm{Y}_{\mathrm{L}(\mathrm{i})}^{(\mathrm{n})} \mathrm{Y}_{\mathrm{L}(\mathrm{j})}^{(\mathrm{n})}\right)=\mathrm{W}_{\mathrm{L}(\mathrm{ij})}^{(\mathrm{n})} \\
& \operatorname{Cov}\left(\mathrm{Y}_{\mathrm{L}(\mathrm{i})}^{(\mathrm{n})} \mathrm{Y}_{\mathrm{L}(\mathrm{j})}^{(\mathrm{n})}\right)=\mathrm{V}_{\mathrm{L}(\mathrm{ij})}^{(\mathrm{n})}=\mathrm{W}_{\mathrm{L}(\mathrm{ij})}^{(\mathrm{n})}-\alpha_{\mathrm{L}(\mathrm{i})}^{(\mathrm{n})} \alpha_{\mathrm{L}(\mathrm{j})}^{(\mathrm{n})}
\end{aligned}
$$

Reverting now to the original ordered observations we clearly have

$$
\mathrm{E}\left(\mathrm{X}_{\mathrm{L}(\mathrm{i})}^{(\mathrm{n})}\right)=\theta+\lambda \alpha_{\mathrm{L}(\mathrm{i})}^{n}
$$




$$
\mathrm{E}\left(\mathrm{X}^{(\mathrm{n})}\right)=\mathrm{P} \beta
$$

where $\underset{\sim}{p}$ is the $(n \times 2)$ matrix $[1, \alpha]$ and $\beta=\left[\begin{array}{ll}\theta & \lambda\end{array}\right]$

The required estimator of the vector $\beta$ by using the extended principle of least-square is given by

$$
\hat{\beta}=\left(\begin{array}{l}
\hat{\theta} \\
\hat{\lambda}
\end{array}\right)=\left(\mathrm{p}^{\prime}\left(\mathrm{V}_{\mathrm{L}}^{(\mathrm{n})}\right)^{-1} \mathrm{p}\right)^{-1} \mathrm{p}^{\prime}\left(\mathrm{V}_{\mathrm{L}}^{(\mathrm{n})}\right)^{-1} \mathrm{X}_{\sim}^{(n)}
$$

where $\underset{\sim}{\underset{\sim}{(n)}}=\left(\mathrm{X}_{\mathrm{L}(1)}, \mathrm{X}_{\mathrm{L}(2)}, \ldots, \mathrm{X}_{\mathrm{L}(\mathrm{n})}\right)$

and $\mathrm{V}_{\mathrm{L}}^{(\mathrm{n})}$ is a variance covariance matrix of order statistics of $\mathrm{Y}$ and

$$
\begin{aligned}
& \operatorname{Var}(\hat{\beta})=\lambda^{2}\left(\mathrm{p}^{\prime}\left(\mathrm{V}_{\mathrm{L}}^{(\mathrm{n})}\right)^{-1} \mathrm{p}\right)^{-1} \\
& \mathrm{p}^{\prime}\left(\mathrm{V}_{\mathrm{L}}^{(\mathrm{n})}\right)^{-1} \mathrm{p}=\left(\begin{array}{c}
1 \\
\alpha^{\prime}
\end{array}\right)\left(\mathrm{V}_{\mathrm{L}}^{(\mathrm{n})}\right)^{-1}\left(\begin{array}{ll}
1 & \left.\alpha^{\prime}\right) \\
& =\left[\begin{array}{ll}
1^{\prime}\left(\mathrm{V}_{\mathrm{L}}^{(\mathrm{n})}\right)^{-1} 1 & 1^{\prime}\left(\mathrm{V}_{\mathrm{L}}^{(\mathrm{n})}\right)^{-1} \alpha \\
\alpha^{\prime}\left(\mathrm{V}_{\mathrm{L}}^{(\mathrm{n})}\right)^{-1} 1 & \alpha^{\prime}\left(\mathrm{V}_{\mathrm{L}}^{(\mathrm{n})}\right)^{-1} \alpha
\end{array}\right]
\end{array}\right.
\end{aligned}
$$

where

$\alpha^{\prime}\left(\mathrm{V}_{\mathrm{L}}^{(\mathrm{n})}\right)^{-1} 1=1^{\prime}\left(\mathrm{V}_{\mathrm{L}}^{(\mathrm{n})}\right)^{-1} \alpha$ (being a scalar matrix)

If we denote by $\Delta$ the determinant of $p^{\prime}\left(V_{L}^{(n)}\right)^{-1} p$, then we have

$$
\left(\mathrm{p}^{\prime}\left(\mathrm{V}_{\mathrm{L}}^{(\mathrm{n})}\right)^{-1} \mathrm{p}\right)^{-1}=\left[\begin{array}{cc}
\frac{\alpha^{\prime}\left(\mathrm{V}_{\mathrm{L}}^{(\mathrm{n})}\right)^{-1} \alpha}{\Delta} & \frac{-\mathrm{l}^{\prime}\left(\mathrm{V}_{\mathrm{L}}^{(\mathrm{n})}\right)^{-1} \alpha}{\Delta} \\
\frac{-1^{\prime}\left(\mathrm{V}_{\mathrm{L}}^{(\mathrm{n})}\right)^{-1} \alpha}{\Delta} & \frac{1^{\prime}\left(\mathrm{V}_{\mathrm{L}}^{(\mathrm{n})}\right)^{-1} \alpha}{\Delta}
\end{array}\right] .
$$

where $\Delta=\left(\alpha^{\prime}\left(\mathrm{V}_{\mathrm{L}}^{(\mathrm{n})}\right)^{-1} \alpha\right)\left(1^{\prime}\left(\mathrm{V}_{\mathrm{L}}^{(\mathrm{n})}\right)^{-1} 1\right)-\left(\alpha^{\prime}\left(\mathrm{V}_{\mathrm{L}}^{(\mathrm{n})}\right)^{-1} 1\right)^{2}$. The estimators are given by

$$
\begin{gathered}
\hat{\theta}=\sum_{\mathrm{i}=1}^{\mathrm{n}} \mathrm{a}_{\mathrm{i}} \mathrm{X}_{\mathrm{L}(\mathrm{i})}^{(\mathrm{n})}, \\
\hat{\lambda}=\sum_{\mathrm{i}=1}^{\mathrm{n}} \mathrm{b}_{\mathrm{i}} \mathrm{X}_{\mathrm{L}(\mathrm{i})}^{(\mathrm{n})},
\end{gathered}
$$


$a=\frac{\alpha^{\prime}\left(\mathrm{V}_{\mathrm{L}}^{(\mathrm{n})}\right)^{-1} \alpha 1^{\prime}\left(\mathrm{V}_{\mathrm{L}}^{(\mathrm{n})}\right)^{-1}-\alpha^{\prime}\left(\mathrm{V}_{\mathrm{L}}^{(\mathrm{n})}\right)^{-1} 1 \alpha^{\prime}\left(\mathrm{V}_{\mathrm{L}}^{(\mathrm{n})}\right)^{-1}}{\left(\alpha^{\prime}\left(\mathrm{V}_{\mathrm{L}}^{(\mathrm{n})}\right)^{-1} \alpha\right)\left(1^{\prime}\left(\mathrm{V}_{\mathrm{L}}^{(\mathrm{n})}\right)^{-1} 1\right)-\left(\alpha^{\prime}\left(\mathrm{V}_{\mathrm{L}}^{(\mathrm{n})}\right)^{-1} 1\right)^{2}}$,

$b=\frac{1^{\prime}\left(\mathrm{V}_{\mathrm{L}}^{(\mathrm{n})}\right)^{-1} 1 \alpha^{\prime}\left(\mathrm{V}_{\mathrm{L}}^{(\mathrm{n})}\right)^{-1}-1^{\prime}\left(\mathrm{V}_{\mathrm{L}}^{(\mathrm{n})}\right)^{-1} \alpha 1^{\prime}\left(\mathrm{V}_{\mathrm{L}}^{(\mathrm{n})}\right)^{-1}}{\left(\alpha^{\prime}\left(\mathrm{V}_{\mathrm{L}}^{(\mathrm{n})}\right)^{-1} \alpha\right)\left(1^{\prime}\left(\mathrm{V}_{\mathrm{L}}^{(\mathrm{n})}\right)^{-1} 1\right)-\left(\alpha^{\prime}\left(\mathrm{V}_{\mathrm{L}}^{(\mathrm{n})}\right)^{-1} 1\right)^{2}}$.

where $a=\left[a_{1}, a_{2}, \ldots \ldots . . a_{n}\right]$ and $b=\left[b_{1}, b_{2}, \ldots \ldots b_{n}\right]$

Variance of these estimators is given as:

$\operatorname{Var}(\hat{\beta})=\left[\begin{array}{rc}\operatorname{var}(\stackrel{\text { 낙 }}{ } & \operatorname{cov}(\theta, \hat{\lambda}) \\ \left.\operatorname{cov}\left(\stackrel{\lambda^{2},}{,} \theta\right)\right) & \operatorname{var}\left(\lambda^{i}\right)\end{array}\right]$,

$\operatorname{Var}(\hat{\theta})=\lambda^{2}\left[\frac{\alpha^{\prime}\left(\mathrm{V}_{\mathrm{L}}^{(\mathrm{n})}\right)^{-1} \alpha}{\left(\alpha^{\prime}\left(\mathrm{V}_{\mathrm{L}}^{(\mathrm{n})}\right)^{-1} \alpha\right)\left(1^{\prime}\left(\mathrm{V}_{\mathrm{L}}^{(\mathrm{n})}\right)^{-1} 1\right)-\left(\alpha^{\prime}\left(\mathrm{V}_{\mathrm{L}}^{(\mathrm{n})}\right)^{-1} 1\right)^{2}}\right]$,

$\operatorname{Var}(\hat{\lambda})=\lambda^{2}\left[\frac{1^{\prime}\left(\mathrm{V}_{\mathrm{L}}^{(\mathrm{n})}\right)^{-1} 1}{\left(\alpha^{\prime}\left(\mathrm{V}_{\mathrm{L}}^{(\mathrm{n})}\right)^{-1} \alpha\right)\left(1^{\prime}\left(\mathrm{V}_{\mathrm{L}}^{(\mathrm{n})}\right)^{-1} 1\right)-\left(\alpha^{\prime}\left(\mathrm{V}_{\mathrm{L}}^{(\mathrm{n})}\right)^{-1} 1\right)^{2}}\right]$,

$\operatorname{Cov}(\stackrel{ }{\theta}, \lambda)=\lambda^{2}\left[\frac{-1^{\prime}\left(\mathrm{V}_{\mathrm{L}}^{(\mathrm{n})}\right)^{-1} \alpha}{\left(\alpha^{\prime}\left(\mathrm{V}_{\mathrm{L}}^{(\mathrm{n})}\right)^{-1} \alpha\right)\left(1^{\prime}\left(\mathrm{V}_{\mathrm{L}}^{(\mathrm{n})}\right)^{-1} 1\right)-\left(\alpha^{\prime}\left(\mathrm{V}_{\mathrm{L}}^{(\mathrm{n})}\right)^{-1} 1\right)^{2}}\right]$

\subsection{Estimation of $\theta$ and $\lambda$ by BLUE}

The pdf of the IRD is given as

$$
f(x)=\frac{2 \lambda^{2}}{(x-\theta)^{3}} \exp \left[-\left(\frac{\lambda}{(x-\theta)}\right)^{2}\right] \quad \theta<x<\infty, \lambda>0 .
$$

Now we have to estimates the location parameter $\theta$ and scale parameter $\lambda$ by the Lloyd's Method. Suppose $r$ Lower record values $\mathrm{X}_{\mathrm{U}(1)}, \mathrm{X}_{\mathrm{U}(2)}, \mathrm{X}_{\mathrm{U}(3)} \cdots . . \mathrm{X}_{\mathrm{U}(\mathrm{r})}$ from the IRD are available. Then, by following the generalized least square approach, we may derive the BLUE of $\theta$ and $\lambda$. The estimates are

$$
\begin{aligned}
& \theta=\sum_{\mathrm{i}=1}^{\mathrm{r}} a_{\mathrm{i}} \mathrm{x}_{\mathrm{U}(\mathrm{i})}, \\
& \lambda^{*}=\sum_{\mathrm{i}=1}^{\mathrm{r}} b_{\mathrm{i}} \mathrm{x}_{\mathrm{U}(\mathrm{i})},
\end{aligned}
$$


where

$$
\begin{aligned}
& \stackrel{*}{\theta}=\frac{1}{\Delta}\left[\alpha^{\prime}\left(V^{(n)}\right)^{-1} \alpha 1^{\prime}-\left(1^{\prime}\left(V^{(n)}\right)^{-1} \alpha\right) \alpha^{\prime}\right]\left(V^{(n)}\right)^{-1} \\
& \hat{\lambda}=\frac{1}{\Delta}\left[-1^{\prime}\left(V^{(n)}\right)^{-1} \alpha 1^{\prime}+\left(1^{\prime}\left(V^{(n)}\right)^{-1} 1 \alpha\right)\right]\left(V^{(n)}\right)^{-1}
\end{aligned}
$$

The variance and covariance of the above estimators are

$$
\begin{aligned}
\operatorname{Var}\left({ }^{*}\right) & =\frac{\boldsymbol{\sigma}^{2} \boldsymbol{\alpha}^{\prime}\left(\mathbf{V}^{(\mathbf{n})}\right)^{-1} \boldsymbol{\alpha}}{\Delta}, \\
\operatorname{Var}\left({ }^{*}\right) & =\frac{\boldsymbol{\sigma}^{2} \boldsymbol{1}^{\prime}\left(\mathbf{V}^{(\mathbf{n})}\right)^{-1} \mathbf{1}}{\Delta}, \\
& \operatorname{Cov}(\stackrel{*}{\theta}, \lambda)=-\frac{\boldsymbol{\sigma}^{2} \mathbf{1}^{\prime}\left(\mathbf{V}^{(\mathbf{n})}\right)^{-1} \boldsymbol{\alpha}}{\Delta} .
\end{aligned}
$$

where

$$
\Delta=\left[\left(\boldsymbol{\alpha}^{\prime}\left(\mathbf{V}^{(\mathrm{n})}\right)^{-\mathbf{1}} \boldsymbol{\alpha}\right)\left(\mathbf{1}^{\prime}\left(\mathbf{V}^{(\mathrm{n})}\right)^{-\mathbf{1}} \mathbf{1}\right)-\left(\mathbf{1}^{\prime}\left(\mathbf{V}^{(\mathrm{n})}\right)^{-1} \boldsymbol{\alpha}\right)^{2}\right]
$$

By making use of the values of means and the variance-covariance's of the $\mathrm{r}^{\text {th }}$ lower record values for the IRD with $\lambda=1$ for $\mathrm{r}$ up to 15 . We determined the coefficients $\mathbf{a}$ and $\mathbf{b}$ from above equations and these are presented in Table 1 and Table 2 respectively for sample size $r \leq 8$. The values of variance covariance's also represented in Table 3 .

Table 1. Coefficients for BLUE of $\theta$ Based on the Lower Record Values from IRD

\begin{tabular}{|c|c|c|c|c|c|c|c|}
\hline $\mathrm{r}$ & $\mathrm{a}_{2}$ & $\mathrm{a}_{3}$ & $\mathrm{a}_{4}$ & $\mathrm{a}_{5}$ & $\mathrm{a}_{6}$ & $\mathrm{a}_{7}$ & $\mathrm{a}_{8}$ \\
\hline 3 & -2.99998 & 3.99999 & & & & & \\
\hline 4 & -1.000001 & -1.99999 & 4.00000 & & & & \\
\hline 5 & -0.499996 & -1.000002 & -1.49996 & 3.99997 & & & \\
\hline 6 & -0.30000 & -0.599998 & -0.900048 & -1.200003 & 4.000003 & & \\
\hline 7 & -0.199999 & -0.399984 & -0.600041 & -0.79988 & -1.00029 & 4.00019 & \\
\hline 8 & -0.142862 & -0.285724 & -0.428537 & -0.571587 & -0.714003 & -0.857235 & 3.99995 \\
\hline
\end{tabular}

The value of each $\mathrm{a}_{1}$ is nearly zeros 


\section{Table 2. Coefficients for BLUE of $\lambda$ Based on the Lower Record Values from IRD}

\begin{tabular}{|c|c|c|c|c|c|c|c|}
\hline $\mathrm{r}$ & \multicolumn{1}{c|}{$\mathrm{b}_{2}$} & $\mathrm{~b}_{3}$ & $\mathrm{~b}_{4}$ & $\mathrm{~B}_{5}$ & $\mathrm{~b}_{6}$ & $\mathrm{~b}_{7}$ & $\mathrm{~b}_{8}$ \\
\hline 3 & 4.513508 & -4.513509 & & & & & \\
\hline 4 & 1.805416 & 3.610803 & -5.416219 & & & & \\
\hline 5 & 1.031654 & 2.063345 & 3.094931 & -6.189930 & & & \\
\hline 6 & 0.687775 & 1.375510 & 2.063427 & 2.751056 & -6.877769 & & \\
\hline 7 & 0.500198 & 1.00037 & 1.50069 & 2.00051 & 2.50161 & -7.50338 & \\
\hline 8 & 0.384778 & 0.769556 & 1.154244 & 1.53937 & 1.92331 & 2.30877 & -8.080019 \\
\hline
\end{tabular}

The value of each $b_{1}$ is nearly zero

Table 3. Variances and Covariance's of BLUE for $\theta$ and $\lambda$

\begin{tabular}{|c|c|c|c|c|c|c|}
\hline $\mathrm{r}$ & 3 & 4 & 5 & 6 & 7 & 8 \\
\hline $\operatorname{Var}(\hat{\theta})$ & 0.999996 & 0.333335 & 0.166667 & 0.099999 & 0.066666 & 0.0 .047620 \\
\hline $\operatorname{Var}(\hat{\lambda})$ & 2.39530 & 1.173000 & 0.77387 & 0.576777 & 0.459494 & 0.381775 \\
\hline $\operatorname{Cov}(\hat{\theta}, \hat{\lambda})$ & -1.504503 & -0.601805 & -0.343886 & -0.229258 & -0.166732 & -0.128258 \\
\hline
\end{tabular}

(Each value is to be multiplied by $\lambda^{2}$ )

\section{An Alternate Linear Estimate (Gupta 1952)}

Lloyd's procedure requires full knowledge of the expectations and the variance covariance matrix of the record values. Specially the covariance may be different to determine. Gupta [12] has proposed a very simple method which is applicable only when the expectations are known. The coefficients of these linear estimates are obtained by assuming the variance matrix to be a unit matrix. Let the linear estimates be

$$
\begin{aligned}
& \hat{\theta}=\sum_{\mathrm{i}=1}^{\mathrm{r}} \mathrm{a}_{\mathrm{i}} \mathrm{X}_{\mathrm{L}(\mathrm{i})}, \\
& \hat{\lambda}=\sum_{\mathrm{i}=1}^{\mathrm{r}} \mathrm{b}_{\mathrm{i}} \mathrm{X}_{\mathrm{L}(\mathrm{i})}, \\
& \mathrm{a}_{\mathrm{i}}=\frac{1}{\mathrm{r}}-\frac{\bar{\mu}_{\mathrm{k}}\left(\mu_{\mathrm{i}}-\bar{\mu}_{\mathrm{k}}\right)}{\sum_{\mathrm{i}=1}^{r}\left(\mu_{\mathrm{i}}-\bar{\mu}_{\mathrm{k}}\right)^{2}}, \\
& \mathrm{~b}_{\mathrm{i}}=\frac{\left(\mu_{\mathrm{i}}-\bar{\mu}_{\mathrm{k}}\right)}{\sum_{\mathrm{i}=1}^{r}\left(\mu_{\mathrm{i}}-\bar{\mu}_{\mathrm{k}}\right)^{2}}, \\
& \bar{\mu}_{\mathrm{k}}=\frac{1}{\mathrm{r}} \sum_{\mathrm{j}=1}^{\mathrm{r}} \mu_{\mathrm{j}} .
\end{aligned}
$$


In matrix notation the variance of the estimates can also be written as

$$
\begin{aligned}
& \operatorname{Var}(\hat{\theta})=\lambda^{2} \mathrm{a}^{\prime} \sum \mathrm{a}, \\
& \operatorname{Var}(\hat{\lambda})=\lambda^{2} \mathrm{~b}^{\prime} \sum \mathrm{b} .
\end{aligned}
$$

\subsection{Estimation of $\theta$ and $\lambda$ by ABLUE}

By utilizing the values of means and the variance-covariance's of the $\mathrm{r}^{\text {th }}$ lower record values for the IRD with $\lambda=1$ for $r$ up to 15 . we have determined below the coefficients a and $\mathrm{b}$ from the above formulas and these are presented in Table 4 and Table 5 respectively. The values of variance covariance's also represented in Table 6.

Table 4. Coefficients for ABLUE of $\theta$ Based on the Lower Record Values from IRD

\begin{tabular}{|l|c|c|c|c|c|c|c|}
\hline $\mathrm{r}$ & $\mathrm{a}_{2}$ & $\mathrm{~A}_{3}$ & $\mathrm{a}_{4}$ & $\mathrm{a}_{5}$ & $\mathrm{a}_{6}$ & $\mathrm{a}_{7}$ & $\mathrm{a}_{8}$ \\
\hline 3 & -3 & 4 & & & & & \\
\hline 4 & -1.92857 & 0.78572 & & & & & \\
\hline 5 & -1.42051 & 0.12895 & 0.90367 & 1.38788 & & & \\
\hline 6 & -1.12642 & -0.08097 & 0.44176 & 0.76847 & 0.99716 & & \\
\hline 7 & -0.935303 & -0.160999 & 0.226150 & 0.468122 & 0.637498 & 0.764532 & \\
\hline 8 & -0.801321 & -0.192918 & 0.111282 & 0.301410 & 0.434496 & 0.534212 & 0.612739 \\
\hline
\end{tabular}

The value of each $a_{1}$ is nearly zero

Table 5. Coefficients for ABLUE of $\lambda$ Based on the Lower Record Values from IRD

\begin{tabular}{|l|l|c|c|c|c|c|c|}
\hline $\mathrm{r}$ & $\mathrm{b}_{2}$ & $\mathrm{~B}_{3}$ & $\mathrm{~b}_{4}$ & $\mathrm{~b}_{5}$ & $\mathrm{~b}_{6}$ & $\mathrm{~b}_{7}$ & $\mathrm{~b}_{8}$ \\
\hline 3 & 4.51351 & -4.51351 & & & & & \\
\hline 4 & 3.22394 & -0.64479 & -2.57915 & & & & \\
\hline 5 & 2.58049 & 0.18699 & -1.00975 & -1.75772 & & & \\
\hline 6 & 2.19197 & 0.46431 & -0.39952 & -0.93942 & -1.31734 & & \\
\hline 7 & 1.93019 & 0.57393 & -0.10419 & -0.52802 & -0.82470 & -1.04721 & \\
\hline 8 & 1.74076 & 0.61906 & 0.05821 & -0.29232 & -0.53769 & -0.72172 & -0.86631 \\
\hline
\end{tabular}

The value of each $b_{1}$ is nearly zero 
Table 6. Variances and Covariance's of ABLUE for $\theta$ and $\lambda$

\begin{tabular}{|c|c|c|c|c|c|c|}
\hline $\mathrm{r}$ & 3 & 4 & 5 & 6 & 7 & 8 \\
\hline $\operatorname{Var}(\hat{\theta})$ & 1 & 0.47704 & 0.296547 & 0.208030 & 0.156713 & 0.12378 \\
\hline $\operatorname{Var}(\hat{\lambda})$ & 2.39530 & 1.50837 & 1.14345 & 0.938416 & 0.805406 & 0.711412 \\
\hline
\end{tabular}

(Each value is to be multiplied by $\lambda^{2}$ )

\subsection{Efficiency of Lloyd's Estimators of $\lambda$.}

We consider the following two situations.

Situation I The parameter $\theta$ is known but $\lambda$ is unknown.

Situation II The parameters $\theta$ and $\lambda$ are unknown.

By using the means, variances and covariance's of the $\mathrm{r}^{\text {th }}$ lower record values for the IRD with $\lambda=1$ for $r$ up to15. We have determined coefficients a for the estimation of $\lambda$ in the first situation; and $\mathbf{b}$ for the estimation of $\lambda$ in the second situation from Lloyd's method. These coefficients are provided in APPENDIX A. The Table 7 shows variances of $\hat{\lambda}$ in two situations and their comparison in terms of the ratio "variance due to situation I / variance due to situation II". The ratio less than 1 indicates the poor performance of $\hat{\lambda}$ in the second situation.

Table 7. Two Variances and Their Ratio

\begin{tabular}{|c|c|c|c|}
\hline $\mathrm{r}$ & $\begin{array}{l}\text { Variance of } \hat{\lambda} \\
\text { ( Situation II ) }\end{array}$ & $\begin{array}{l}\text { Variance of } \hat{\lambda} \\
\text { (Situation I ) }\end{array}$ & Ratio \\
\hline 3 & 2.39530 & 0.131768 & 0.05501 \\
\hline 4 & 1.173000 & 0.086498 & 0.07374 \\
\hline 5 & 0.773872 & 0.064324 & 0.08311 \\
\hline 6 & 0.576777 & 0.051185 & 0.08874 \\
\hline 7 & 0.459494 & 0.042497 & 0.09248 \\
\hline 8 & 0.381775 & 0.036328 & 0.09515 \\
\hline 9 & 0.326500 & 0.0317225 & 0.09715 \\
\hline 10 & 0.285156 & 0.0281488 & 0.09871 \\
\hline 11 & 0.253159 & 0.0253045 & 0.09901 \\
\hline 12 & 0.227583 & 0.0229792 & 0.10097 \\
\hline 13 & 0.206697 & 0.0210461 & 0.10182 \\
\hline 14 & 0.189311 & 0.019412 & 0.10253 \\
\hline 15 & 0.174623 & 0.0180134 & 0.10315 \\
\hline
\end{tabular}


The following graph is useful in investigating the efficiency of these approaches.

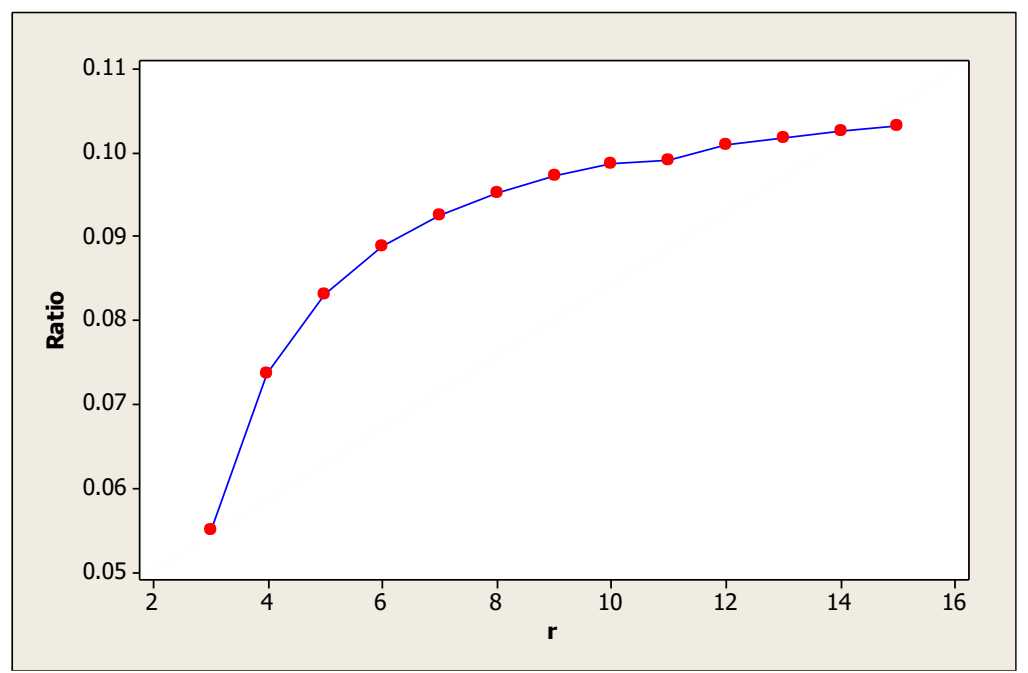

Figure 1. Efficiency of Second Approach Relative to First Approach

From Figure 1 it can be easily concluded that Lloyd's method based on one unknown parameter is much more efficient than Lloyd's method for the estimation of $\lambda$ when both $\lambda$ and $\mu$ are unknown. Even if the $r$ increases the efficiency of single parameter approach still remains much superior.

\subsection{Relative Efficiency}

Efficiency is defined as the ratio of variances of the estimator of BLUEs to variances of the estimator to alternate estimates (Gupta) for sample size $3 \leq n \leq 8$. These efficiencies are presented in Table 8 .

Table 8. Relative Efficiencies of Lloyd's Method and Gupta's Method of Estimation of $\theta$ and $\lambda$

\begin{tabular}{|c|c|c|c|c|c|c|}
\hline $\mathbf{n}$ & $\operatorname{Var}\left(\hat{\mu}_{\text {Lyold }}\right)$ & $\operatorname{Var}\left(\hat{\mu}_{\text {Gupta }}\right)$ & R.E & $\operatorname{Var}\left(\hat{\lambda}_{\text {Lyold }}\right)$ & $\operatorname{Var}\left(\hat{\lambda}_{\text {Gupta }}\right)$ & R.E \\
\hline 3 & 1.00000 & 1.00000 & 100.000 & 2.39530 & 2.39530 & 100.000 \\
\hline 4 & 0.33333 & 0.47704 & 69.876 & 1.17300 & 1.50837 & 77.766 \\
\hline 5 & 0.16667 & 0.29655 & 56.202 & 0.77387 & 1.14345 & 67.679 \\
\hline 6 & 0.09999 & 0.20803 & 48.065 & 0.57678 & 0.93842 & 61.463 \\
\hline 7 & 0.06667 & 0.15671 & 42.541 & 0.45949 & 0.80541 & 57.051 \\
\hline 8 & 0.04762 & 0.12378 & 38.471 & 0.38177 & 0.71141 & 53.664 \\
\hline \multicolumn{7}{|c|}{ Note: $\quad \operatorname{R.E}(1)=\operatorname{Var}\left(\hat{\theta}_{\text {Lyold }}\right) / \operatorname{Var}\left(\hat{\theta}_{\text {Gupta }}\right)$} \\
\hline
\end{tabular}

This approximate method suggests that the efficiency of the determination of linear estimates seems particularly sensitive to change in the coefficients and may not be chosen 
for conveniences. We can't replace Gupta method with Lloyd's method due to point of view of efficiency. The behaviour of approximate method is vary distribution to distribution. So we have to take another approximate linear estimation method namely as Weiss [13] method.

\section{Estimation of $\theta$ and $\lambda$ by Weiss Approximation}

Suppose we have an lower record random sample $X_{\mathrm{L}(1)}, X_{\mathrm{L}(2)}, \mathrm{X}_{\mathrm{L}(3)}, \ldots, \mathrm{X}_{\mathrm{L}(\mathrm{n})}$ from the Inverse Rayleigh density

$$
f(x)=\frac{2 \lambda^{2}}{x^{3}} \exp \left[-\left(\frac{\lambda^{2}}{x^{2}}\right)\right] x, \lambda>0 .
$$

In which $\lambda$ is a scale parameter. It is desired to estimate by means of suitable linear combination of lower record values. Let the estimate of the scale parameter for IRD by Weiss method is

$$
\hat{\lambda}=\frac{n+1}{n-1} \sum_{r=1}^{n-2} g\left[G^{-1}(r / n)\left\{Y_{L(r+2)}-Y_{L(r+1)}\right\} .\right.
$$

This estimate is consistent but is biased. If we consider as

$\hat{\lambda}=k \sum_{r=1}^{n-2} g\left[G^{-1}(r / n)\left\{Y_{L(r+2)}-Y_{L(r+1)}\right\}\right.$

where $k=\frac{1}{\sum_{r=1}^{n-2} g\left[G^{-1}(r / n)\left\{\alpha_{(r+2)}-\alpha_{(r+1)}\right\}\right.}$,

such that $E(\hat{\lambda})=\lambda$.

From the reduced Rayleigh distribution and computing the fractile with making some relation with gamma distribution and after evaluate and simplifying we have the estimate of scale parameter for IRD by Weiss as

$$
\hat{\lambda}=\frac{\sum_{r=1}^{n-2}\left[\frac{2}{\sqrt{r}} \prod_{i=1}^{r-1}\left(\frac{n-i}{n}\right)\left(\sum_{i=0}^{r-1} \ln \left(\frac{n}{n-i}\right)\right)^{r+1 / 2}\right]\left(Y_{L(r+2)}-Y_{L(r+1)}\right)}{\sum_{r=1}^{n-2}\left[\frac{2}{\sqrt{r}} \prod_{i=1}^{r-1}\left(\frac{n-i}{n}\right)\left(\sum_{i=0}^{r-1} \ln \left(\frac{n}{n-i}\right)\right)^{r+1 / 2}\right]\left(\alpha_{(r+2)}-\alpha_{(r+1)}\right)} .
$$

In matrix notation the variance of the estimates can also be written as

$$
\mathbf{V}(\hat{\lambda})=\lambda^{2} h^{\prime} \mathbf{V} h \text {. }
$$


Table 9. Coefficients by Weiss Approximation of Scale Parameter of IRD using Lower Record Values for $\mathbf{3} \leq \mathrm{n} \leq \mathbf{8}$

\begin{tabular}{|l|l|l|l|l|l|l|l|}
\hline $\mathrm{n}$ & $\mathrm{h}_{2}$ & $\mathrm{~h}_{3}$ & $\mathrm{~h}_{4}$ & $\mathrm{~h}_{5}$ & $\mathrm{~h}_{6}$ & $\mathrm{~h}_{7}$ & $\mathrm{~h}_{8}$ \\
\hline 3 & 4.51351 & -4.51351 & & & & & \\
\hline 4 & 1.7744 & 3.703836 & -5.47823 & & & & \\
\hline 5 & 1.03344 & 1.681455 & 4.077505 & -6.79240 & & & \\
\hline 6 & 0.716542 & 0.908785 & 2.023685 & 4.780722 & -8.429734 & & \\
\hline 7 & 0.547981 & 0.542300 & 1.103202 & 2.52061 & 5.66970 & -10.38392 & \\
\hline 8 & 0.445653 & 0.343097 & 0.64171 & 1.399153 & 3.120349 & 6.70516 & -12.65514 \\
\hline
\end{tabular}

Weiss approximation only considers the estimation of the scale parameter but we can also estimate the location parameter by Weiss method. The following relation is true for the distribution of the type $\mathrm{F}\left(\frac{\mathrm{x}-\theta}{\lambda}\right)$ i.e $\cdot$

$\mathrm{E}(\overline{\mathrm{x}})=\theta+\mathrm{k} \lambda$ also we have $E(\hat{\lambda})=\lambda$ and $\mathrm{E}(\overline{\mathrm{x}})=\mathrm{E}(\mathrm{x})$. From the pdf of Lower record density of IRD we have

$$
\mathrm{E}\left(\mathrm{X}_{\mathrm{L}(\mathrm{n})}\right)=\theta+\frac{\sqrt{n-1 / 2}}{\sqrt{n}} \lambda
$$

If we denote $\hat{\mu}$ as the estimate of $\mu$ then by Weiss method

$$
\text { 늣 }=\sum_{i=2}^{n}\left(\frac{1}{n}-\frac{\sqrt{n-1 / 2}}{\sqrt{n}} \lambda\right) X_{L(i)} \text {, }
$$

$\hat{\lambda}$ is the scale estimate obtained by Weiss method. Expression for variance is also obtained as

$\operatorname{Var}(\hat{\theta})=\lambda^{2} \frac{1}{(\mathrm{n}-1)^{2}}\left[\frac{\sqrt{\mathrm{i}-1}}{\Gamma_{\mathrm{i}}}-\left(\frac{\sqrt{\mathrm{i}-1 / 2}}{\Gamma_{\mathrm{i}}}\right)^{2}\right]+\left(\frac{\sqrt{\mathrm{n}-1 / 2}}{\Gamma_{\mathrm{n}}}\right)^{2}$,

$\operatorname{Var}(\hat{\lambda})=2 \operatorname{Var}\left(X_{n}\right)$.

Table 10. Coefficients by Weiss approximation of Location Parameter of IRD using Lower Record Values for $3 \leq n \leq 8$

\begin{tabular}{|l|l|l|l|l|l|l|l|}
\hline $\mathrm{n}$ & $\mathrm{h}_{22}$ & $\mathrm{~h}_{23}$ & $\mathrm{~h}_{24}$ & $\mathrm{~h}_{25}$ & $\mathrm{~h}_{26}$ & $\mathrm{~h}_{27}$ & $\mathrm{H}_{28}$ \\
\hline 3 & -2.6667 & 3.3333 & & & & & \\
\hline 4 & -0.732826 & -1.80152 & 3.28435 & & & & \\
\hline 5 & -0.300862 & -0.614926 & -1.77618 & 3.49197 & & & \\
\hline 6 & -0.14588 & -0.229736 & -0.716044 & -1.91864 & 3.84363 & & \\
\hline 7 & -0.07625 & -0.073976 & -0.298248 & -0.864985 & -2.12412 & 4.29477 & \\
\hline 8 & -0.040462 & -0.002385 & -0.113254 & -0.394478 & -1.03353 & -2.3645 & 4.82361 \\
\hline
\end{tabular}


Table 11. Variances and Covariance's of Weiss Approximation for $\theta$ and $\lambda$

\begin{tabular}{|l|l|l|l|l|l|l|}
\hline $\mathrm{n}$ & 3 & 4 & 5 & 6 & 7 & 8 \\
\hline $\operatorname{Var}(\hat{\lambda})$ & 2.3953 & 1.17316 & 0.778647 & 0.588645 & 0.480199 & 0.412684 \\
\hline $\operatorname{Var}(\hat{\mu})$ & 0.972097 & 0.32556 & 0.165257 & 0.101525 & 0.069937 & 0.052122 \\
\hline
\end{tabular}

\subsection{Relative Efficiency}

Efficiency is defined as the ratio of variances of the estimator of BLUEs to variances of the estimator to Weiss method for sample size $3 \leq n \leq 8$. These efficiencies are presented in Table 12.

\section{Table 12. Relative Efficiencies of Lloyd's Method and Weiss Method of} Estimation of $\boldsymbol{\theta}$ and $\lambda$

\begin{tabular}{|l|l|l|l|l|l|l|}
\hline $\mathbf{n}$ & $\operatorname{Var}\left(\hat{\lambda}_{\text {Lyold }}\right)$ & $\operatorname{Var}\left(\hat{\lambda}_{\text {Weiss }}\right)$ & $\mathbf{R . E}$ & $\operatorname{Var}\left(\hat{\mu}_{\text {Lyold }}\right)$ & $\operatorname{Var}\left(\hat{\mu}_{\text {Weiss }}\right)$ & R.E \\
\hline $\mathbf{3}$ & 2.39530 & 2.39530 & 100.000 & 1.00000 & 1.00999 & 99.0109 \\
\hline $\mathbf{4}$ & 1.17300 & 1.17316 & 99.986 & 0.33333 & 0.340108 & 98.0071 \\
\hline $\mathbf{5}$ & 0.77387 & 0.778647 & 99.386 & 0.16667 & 0.172332 & 96.7145 \\
\hline $\mathbf{6}$ & 0.57678 & 0.588645 & 99.984 & 0.09999 & 0.105488 & 94.7880 \\
\hline $\mathbf{7}$ & 0.45949 & 0.480199 & 95.687 & 0.06667 & 0.0723767 & 92.1153 \\
\hline $\mathbf{8}$ & 0.38177 & 0.412684 & 93.506 & 0.04762 & 0.0537296 & 88.6290 \\
\hline
\end{tabular}

This approximate method suggests that the efficiency of linear estimates do not seem sensitive to change in the coefficients, and therefore may be selected for conveniences. We can replace Weiss method with Lloyd's method from the point of view of efficiency.

\section{Conclusion}

For the estimation of location and scale parameters, the methods Lloyd and Gupta are applied and it is found that Lloyd's method gives higher efficiency. The important contribution of this research deliberation lies in determining the coefficients of each linear estimator of $\lambda$ and $\theta$ due to Lloyd's method. This information is also used for the computation of their variances and covariance's for sample size up to 15 . Critical study are made on the Exact and approximate method of estimation for estimating the location and scale parameter of IRD. An alternate best linear estimator gives very poor approximation in case of IRD. So our focus in this study for two parametric IRD is to find another approximate method which gives high efficiency with Lloyd method. This approximate method known as Weiss's method. This is the method of estimating the single parameter only that is the scale parameter. But in this study we have to modified this method for estimating the location parameter also. These location and scale estimators are compared with the Lloyd method and concluded that in all cases efficiency is very high so this approximation is good as compared to Gupta method. When $\boldsymbol{\theta}$ and $\lambda$ are both unknown Lloyd's method still operates more efficiently than Gupta's method, especially when the sample size takes a higher number. 


\section{References}

[1] K. N. Chandler, "The Distribution and frequency of record values", Journal of Royal statistics, series B, vol. 14 no. 2, (1952), pp. 220-228.

[2] N. Balakrishan and P. S. Chan, "On the normal Record values and associated Inference", Statistics and Probability Letters, vol. 39, (1998), pp. 73-80.

[3] M. Ahsanullah, "Record Values- Theory and Application", University Press of America, Inc. New York. Oxford, (2004).

[4] A. A. Soliman, A. A. Ellah and K. S. Sultan, "Comparison of estimates using record statistics from Weibull model: Bayesian and non-Bayesian approaches", Computational Statistics and Data Analysis, vol. 51, no. 3, (2006), pp. 2065-2077.

[5] M. I. Hendi, S. E. Abu-Yousef and A. A. Alraddadi, "A Baysian analysis of record statistics from Rayleigh model”, International Mathematical Forum, vol. 2, no. 13, (2007), pp. 619-631.

[6] J. Ahmadi, and M. Doostparast, "Statistical inference based on k-records. Mashhad", R. J. Math, Sci, vol. 1, no. 1, (2008), pp. 67-82.

[7] K. S. Sultan, "Record Values from the Inverse Weibull Lifetime Model: Different Methods of Estimation", Intelligent Information management, vol. 2, (2010), pp. 631-636.

[8] A. Azaz, and A. S. Akhter, "Estimation of the scale and location parameters based upon the upper record values of Rayleigh distribution from type II singly and doubly censored data", Proceedings third international conference on statistical sciences. University of the Punjab, (2010).

[9] S. Dey, and T. Dey, "Bayesian estimation of the Parameter and reliability of a Rayleigh distribution using records", Model Assisted Statistics and Application, vol. 7, no. 2, (2012), pp. 81-90.

[10] E. A. Amin, Bayesian and non-Baysian estimation of $\mathrm{P}(\mathrm{Y}<\mathrm{X})$ from Type I generalized logistic distribution based on lower record values. Australian journal of Basic and Applied sciences, vol. 6, no. 3, (2012), pp. 616-62.

[11] A. K. Hamid, and S. A. Imtiyaz, "Distribution Properties of Order Statistics and Record Statistics", Statitsics in twenty first century: special volume in honour of distinguished Professor DR. MIR MASOOM ALI on the occasion of his $75^{\text {th }}$ Birthday Anniversary. PJSOR, vol. 8, no. 3, (2012), pp. 573-581.

[12] A. K. Gupta, "Estimation of the Mean and standard deviation of a Normal Population from a censored sample", Biometrica, vol. 39, no. 3/4, (1952), pp. 260-273.

[13] L. Weiss, "On the estimation of scale parameters", Naval Res. Logistics Quart.8, (1961), pp. 245-256. 
International Journal of Advanced Science and Technology Vol.102 (2017) 